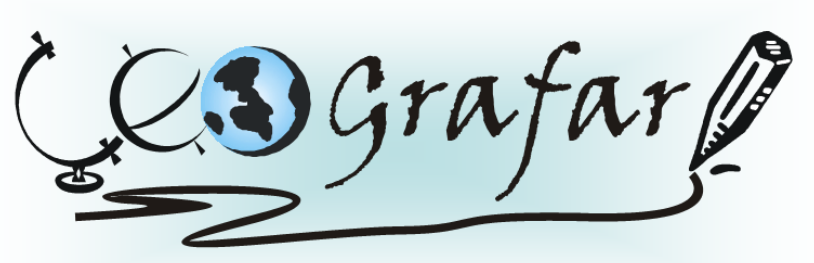

Revista Eletrônica do Programa de Pós-Graduação em Geografia - UFPR

\title{
TERRITÓRIO, DESIGUALDADE E EXPANSÃO DO CAPITAL: A CENTRALIDADE DA INDÚSTRIA DO PETRÓLEO EM MACAÉ/RJ
}

\section{TERRITORY, INEQUALITY AND EXPANSION OF CAPITAL: THE CENTRALITY OF THE OIL INDUSTRY IN MACAÉ/RJ}

\author{
Lígia Jesus de Carvalho \\ Mestranda em Psicossociologia de \\ Comunidades e Ecologia Social \\ Universidade Federal do Rio de Janeiro \\ Rio de Janeiro, RJ, Brasil \\ e-mail: ligia.carvalho.ufrj@gmail.com \\ Carlos Frederico Bernardo Loureiro \\ Prof. Dr. da Faculdade de Educação \\ Universidade Federal do Rio de Janeiro \\ Rio de Janeiro, RJ, Brasil \\ e-mail: fredericoloureiro89@gmail.com
}

\begin{abstract}
RESUMO
O presente trabalho, resultante de pesquisa de mestrado, analisou a organização do território no município de Macaé/Rio de Janeiro (RJ) mediante a centralidade da cadeia petrolífera da Bacia de Campos para a economia e a organização social regional, e os conflitos sociais resultantes deste processo, analisando particularmente a conjuntura de injustiça ambiental presente no bairro periférico do Lagomar. A exaltação do nacionalismo energético sustentada pelo pilar do petróleo, abre margem para o discurso ideológico de distribuição igualitária de riquezas e prosperidade material evidenciado no Norte Fluminense, visto que o crescimento econômico da região não tem se refletido em desenvolvimento social igualitário ou em garantia de trabalho. A dependência material em torno de recursos finitos, flexibiliza a garantia de direitos sociais, políticas públicas e leis ambientais, com a finalidade de garantir a intensificação da exploração do trabalho e de recursos naturais. As periferias do município de Macaé, que surgem por consequência do fluxo imigratório, fruto da chegada da indústria do petróleo na região, condensam as consequências sociais de um processo de avanço industrial em que o ordenamento territorial reproduz e espacializa as desigualdades.
\end{abstract}

Palavras-chave: Norte Fluminense; Injustiça ambiental; Espaço urbano; Periferias. 


\begin{abstract}
This work, resulting master's research, analyzed the organization of the territory in the city of Macaé/Rio de Janeiro by the centrality of the oil chain Campos Basin to the economy and the regional social organization, and social conflicts resulting from this process, analyzing particularly the situation of environmental injustice present in the peripheral district of Lagomar. The exaltation of energetic nationalism sustained by pillar oil, makes room for the ideological discourse of the equalitarian distribution of wealth and material prosperity evidenced in the Norte Fluminense since the region's economic growth it has not been reflected in egalitarian social development or labor warranty. The material dependence around finite resources, make flexible the guarantee of social rights, public policy and environmental laws, in order to ensure the intensification of the exploitation of labor and natural resources. The peripheries of the city of Macae, which arise coming from of the immigration flow, result of the oil industry's arrival in the region, condenses the social consequences of a process of industrial advancement that territorial organization reproduces and spatializes the inequalities.
\end{abstract}

Keywords: Norte Fluminense; Environmental injustice; Urban space; Peripheries.

\title{
INTRODUÇÃO
}

O município de Macaé, no estado do Rio de Janeiro/Brasil, a partir da instalação da cadeia produtiva do petróleo desde a década de 1980, se desenvolveu mediante centralidade de matriz energética finita e do extrativismo mineral de mercado, favorecendo a expansão do capital dentro dos moldes de desenvolvimento liberal e dependente. Para além da dependência material à extração mineral, especificamente no caso em estudo, essas relações sociais são mediadas por uma ideologia de valorização permanente do mercado de trabalho voltado para o setor do petróleo. Ideologia esta que vem aliada ao discurso da gestão ambiental racional, enquanto mecanismo técnico capaz de mitigar os impactos socioambientais, e da promessa de altos ganhos financeiros e estabilidade econômica para a população a serem garantidos pela exploração petrolífera.

A análise do uso dos royalties, principal fonte de recursos oriundos do petróleo na composição orçamentária municipal - cuja finalidade seria mitigar os impactos ambientais e sociais gerados nos municípios impactados - indica que estes são aplicados em incumbências que visam à manutenção deste status de arrecadação, por meio da defesa da indústria do petróleo como única alternativa de desenvolvimento possível para a região, cuja "vocação natural" seria essa 
modalidade de extrativismo mineral. O que gera um ciclo preocupante de dependência econômica regional e de reprodução de ideologias que naturalizam o atual modo de produção.

O município de Macaé ao tornar-se, na primeira década de 2000, a principal localidade na região norte fluminense para as instalações e bases operacionais da indústria do petróleo, alcançou crescimento econômico e índice diferenciado em relação à oferta de empregos formais gerados. As periferias do município de Macaé, que surgem por consequência dos fluxos migratórios, fruto da chegada da indústria do petróleo na região, condensam as consequências sociais de um processo de avanço industrial em que o ordenamento territorial reproduz e espacializa as desigualdades. Dentre essas localidades periféricas situadas em Macaé nos aprofundaremos neste estudo sobre o território do Bairro Lagomar.

A escolha por este bairro deu-se em função deste ser resultante do adensamento populacional irregular (ocupada principalmente por migrantes de baixa renda), por consequência da rápida urbanização do município desde o estabelecimento da indústria do petróleo. O bairro é limítrofe ao Parque Nacional da Restinga de Jurubatiba, o que resulta em configuração de conflito de uso do território. É também uma área de habitação irregular e acesso limitado a direitos sociais básicos, o que resulta no desencadeamento de outros agravantes que se referem à precariedade de saneamento e água canalizada, além das condições de violência, que colocaram as periferias de Macaé entre as áreas mais violentas do estado do Rio de Janeiro (WAISELFISZ, 2004; COSTA, 2009). Esse bairro, portanto, exemplifica uma situação de injustiça ambiental, que se define enquanto tal quando na sociedade se destina a maior carga dos danos ambientais a trabalhadores, povos tradicionais ou grupos étnico-raciais discriminados, ameaçando a integridade da saúde ambiental e comprometendo a sua reprodução social (ACSELRAD, 2009 e 2004).

Em termos metodológicos, cabe esclarecer que este trabalho resultou de pesquisa de mestrado cujo recorte foi fundamentado nos procedimentos metodológicos de interpretação dos dados em relação aos índices demográficos da cidade de Macaé, com enfoque no bairro Lagomar, a partir de análises de fontes secundárias, respaldadas na pesquisa domiciliar realizada pelo programa Macaé 
Cidadão - 2006/2007, dados estatísticos do Instituto Brasileiro de Geografia e Estatística - IBGE/2010, documentos e sites oficiais do governo local.

O argumento central defendido no artigo é de que as formas econômicas de desenvolvimento presentes em Macaé, atreladas à dependência em torno dos royalties e da ausência de diversificação dos setores produtivos, reproduzem formas de dominação, por intermédio da legitimação das desigualdades e consequente reorganização do território. Nos termos de Harvey (2005), a produção capitalista do espaço agudiza os conflitos ambientais, delimitam zonas de sacrifício e naturaliza o padrão de desenvolvimento determinado por forças hegemônicas da região.

\section{A centralidade da indústria do petróleo em Macaé}

Inserido em um desenvolvimento capitalista energeticamente baseado em combustíveis fósseis (ALTVATER, 2010), o Brasil acompanhou a tendência global de acumulação voltada para as atividades petrolíferas, em face da reprimarização de sua economia e em consonância ao "atual padrão de desenvolvimento regional brasileiro, fragmentado e espalhado territorialmente" (BARCELOS, 2015, p.10). O resultado foi a reorganização territorial com intensa pressão política e econômica sobre as legislações ambientais, os trabalhadores e povos tradicionais, aprofundamento das desigualdades sociais e dependência material em torno desses recursos finitos.

O movimento de expansão do capitalismo "criou a globalização, [e neste] globalizou-se a demanda e acirrou-se a disputa pelos recursos energéticos." (HERNANDEZ; BERMANN, 2010, p. 145). Afinal, não há atividade econômica expansiva e intensiva sem energia; e particularmente os combustíveis fósseis possuem qualidades que permitem alto rendimento econômico, energético e fácil disponibilidade para seu uso em diferentes lugares. Neste contexto, em que se consolida a centralidade do petróleo para o capitalismo no final do século XIX e nos séculos $\mathrm{XX}$ e $\mathrm{XXI}$, em termos de necessidade energética para o desenvolvimento econômico, o mar se torna o “novo' ambiente a ser tomado pelo capital." (MENDONÇA, 2015, p. 293).

Por sua vez, os municípios que sedem a base logística das atividades offshore ou ainda que são indiretamente afetados por esta, através da Lei 
9.478/1997, conhecida como a Lei do Petróleo, recebem compensações financeiras comumente sob a forma de royalties e participações especiais afim de mitigar os impactos ambientais e sociais gerados. O que leva a profunda "mudança no quadro econômico dos municípios fluminenses com maciços investimentos, principalmente naqueles diretamente relacionados às atividades petrolíferas." (PACHECO, 2015, p. 03)

Na Tabela consta a arrecadação de royalties e participações especiais dos municípios pertencentes à Ompetro (Organização dos Municípios Produtores de Petróleo). Nesta é possível verificar que, em 2014, somente no município de Macaé, os royalties renderam aos cofres municipais aproximadamente 548 milhões de reais. O que dispõe na segunda posição em arrecadação de royalties na região Norte do estado do Rio de Janeiro em função do seu expressivo potencial de produção petrolífera.

Tabela 1 - Arrecadação de royalties e participações especiais dos municípios pertencentes à Ompetro.

\begin{tabular}{|c|c|c|c|c|c|c|}
\hline \multirow{2}{*}{ Municipios } & \multicolumn{6}{|c|}{ Royalties + Participação Especial } \\
\hline & 2009 & 2010 & 2011 & 2012 & 2013 & 2014 \\
\hline Amaçào dos Búzios & RS 41.897.724,65 & RS $54.433 .595,43$ & RS $64.834 .653,70$ & RS $82.693 .743,10$ & RS 78.203.220,50 & RS $92.838 .065,15$ \\
\hline Arraial do Cabo & RS 5.216.022,59 & RS5.753.840,31 & RS 26.548.891,01 & RS $44,480.524,01$ & RS $44.086547,66$ & RS $46.294 .775,38$ \\
\hline Cabo Fno & RS 133.778 .273 .24 & RS $190.041 .949,99$ & RS $245.857 .232,03$ & RS 324.982.556,21 & RS 292.232.851,77 & RS $327.547 .737,11$ \\
\hline Camposdos Goy & RS $993.167 .279,11$ & RS $1.016 .021 .871,72$ & RS 1.231.637.781.97| & RS $1.354 .233 .313,47$ & RS $1.121 .075 .458,74$ & RS 1.286 .920 .73595 \\
\hline Carapebus & RS $22.745 .005,61$ & RS $29.294 .670,39$ & RS $34.802 .768,18$ & RS $38.640 .170,21$ & RS $37.145 .406,03$ & RS $41.499 .852,91$ \\
\hline Casimiro de Abreu & RS $56.490 .065,54$ & RS 72.096.769,23 & RS $99.4399666,64$ & RS $112.016 .299,75$ & RS $109.723 .361,10$ & RS $117.076 .833,93$ \\
\hline Macaé & RS 387.541.067,11 & RS $410.516 .330,10$ & RS 482.234.671,56 & RS $538.654 .219,32$ & RS $502.865 .600,53$ & RS $548.171 .100,40$ \\
\hline Niteröi & RS 33957924,44 & RS $41.932 .167,05$ & RS $64.486 .783,68$ & RS $114.460 .860,55$ & Rs $123.074 .151,12$ & RS 206.408.566,35 \\
\hline Quissamå & RS $90969.685,66$ & RS $90.510 .827,62$ & RS $92.661381,55$ & RS $102.831 .908,28$ & RS $92.767 .436,08$ & RS 94.208.926,94 \\
\hline Rio das Ostras & RS 284.555 .96890 & RS $248,427,458,73$ & RS $324.800 .547,05$ & RS $348.835 .716,27$ & RS $289,333.003,20$ & RS $329.584 .159,08$ \\
\hline São Joào da Bama & RS $168.329 .125,44$ & RS $203.028 .163,85$ & RS $251.512 .931,02$ & RS $233.262 .154,92$ & RS $193.689 .360,84$ & RS 246.968.015,77 \\
\hline
\end{tabular}

Fonte:http://www.ompetro.org.br/index.php/52-ompetro/arrecadacao/464-balanco-arrecadacaoryalties. Acesso em: 16 de maio de 2015.

Visando à manutenção deste status de arrecadação o governo municipal investe fortemente no desenvolvimento deste setor produtivo, com políticas públicas de infraestrutura, de serviços e de formação profissional direcionadas para atender ao mercado inserido na cadeia produtiva do petróleo. O resultado deste processo é o encadeamento da economia local indireta ou diretamente fomentada pela indústria do petróleo, que passam a depender imediatamente desta. O que, apesar de manter 
em curto prazo a economia aquecida, não tem se mostrado eficiente em um cenário de crise no setor. Em função da crescente queda no preço do barril de petróleo, que em janeiro de 2015 já registrava uma baixa de $50 \%$ por cento do valor, quando comparado a $2009^{1}$, as receitas dos municípios dependentes dos royalties do petróleo têm sido diretamente afetadas.

A dependência econômica em torno dos royalties, atrelada à não diversificação dos setores produtivos, em tempos de crise de petróleo confluiu no despreparo da economia dos municípios produtores do Norte Fluminense para o enfretamento da situação. O presidente da Ompetro (e prefeito do município de Macaé), ao tratar sobre crise reconheceu abertamente que:

A crise não reduz só a arrecadação de royalties. Essas cidades dependem da economia do petróleo, por isso todos os empregos acabam afetados. $O$ desemprego começa nos gabinetes dos diretores das empresas e vai até a padaria do último bairro do município. (ALERJ. 2015. [n.p]. ${ }^{2}$ ).

Essa realidade identificada em Macaé se coaduna com o que Harvey (2005) chamou de produção capitalista do espaço. O espaço capitalista é produzido por meio da reprodução alienada da vida cotidiana que é mediada pelo processo de produção, circulação e realização de mercadorias, cujo objetivo direto é o lucro, portanto, a reprodução do capital e sua acumulação. É um cotidiano que produz relações alienadas, pois deve expandir o capital e reformar constantemente o processo de trabalho e as relações sociais na produção e na circulação.

Para que esse ciclo não seja rompido ou estagnado, o capitalismo necessita do Estado, cuja forma de existência se altera em função dos interesses das forças econômicas dominantes. Assim, é o Estado que se torna o elemento decisivo para a produção espacial no capitalismo ao garantir a infraestrutura necessária à circulação das mercadorias e ao mediar e financiar o ordenamento do território de modo a localizar espacialmente as classes sociais, serviços e mercados.

\footnotetext{
${ }^{1}$ Petróleo nunca voltará ao patamar de US\$ 100 o barril, afirma príncipe saudita. Reportagem de 12/01/2015. Disponível em: http://www.redebrasilatual.com.br/economia/2015/01/petroleo-nunca-voltara-ao-patamar-de-us100-o-barril-afirma-principe-saudita-5553.html . Acesso em: 16. mai. 2015.

2 Reportagem. Prefeitos buscam solução política para enfrentar crise do petróleo. 31 mar. 2015. Disponível em: <http://www.ompetro.org.br/index.php/noticias/1874-prefeitos-buscam-solucao-politicapara-enfrentar-crise-do-petroleo>. Acesso em: 29. mai. 2015.
} 


\section{A reorganização de Macaé e a dependência do extrativismo mineral}

O município de Macaé, desde a chegada da empresa Petrobras, em 1978, e "demais empresas ligadas à economia petrolífera, como Halliburton, Schlumberger, Pride, Transocean e Brastech, que lá se instalaram desde a década de 1980 e, de maneira mais expressiva, a partir de 1997" (PAGANOTO, 2008, p. 50) foi fortemente impactado com as reestruturações econômicas resultantes desta indústria, que praticamente eliminou a pequena produção rural, a pesca artesanal, e as práticas culturais tradicionais. O que resultou em um "processo de rearranjo econômico, político, demográfico e territorial" (SIRELLI et al., 2013, p. 190) em torno desta estatal e a uma cultura de "cidade de passagem", em que as pessoas residem com uma perspectiva de permanecer enquanto o petróleo der retorno econômico.

Segundo Terra e Ressiguier (2011, p. 152), ao "concentrar capitais e gerar milhares de empregos diretos e indiretos, a atividade petrolífera faz de Macaé um dos mais importantes centros de migração" na região do estado do Rio de Janeiro em que esta atividade econômica é dominante, juntamente com Campos dos Goytacazes, que detém a maior arrecadação de royalties dentre os municípios beneficiados. A Tabela, contempla o número de habitantes desde 1970 até 2009 dos municípios do Norte Fluminense, o que nos permite dimensionar as proporções de dinâmica populacional quando nos referimos ao fenômeno migratório que é observado em Macaé, concomitante ao período em que ocorreu a ascensão econômica, voltada para as atividades de extração de petróleo, ao final da década de 1980.

Apesar do expressivo número de habitantes que Campos dos Goytacazes recebeu neste mesmo período, é importante mencionar que a extensão territorial do mesmo $\left(4.026,696 \mathrm{~km}^{2}\right)$ possibilita em tese uma melhor distribuição populacional. De acordo com o último censo do IBGE (2010) o município apresentou densidade demográfica de 115,16 hab/km². Em comparação, Macaé, com um território aproximadamente três vezes menor $\left(1.216,846 \mathrm{~km}^{2}\right)$, neste mesmo censo apresentou densidade demográfica de 169,89 hab/km².

Quando calculamos a diferença no crescimento populacional no intervalo entre uma década e outra é possível notar, de acordo com a Tabela , que em Macaé esse aumento ocorreu em ritmo muito mais acelerado, quando comparado aos 
demais municípios do Norte Fluminense. Macaé no censo 2000 estava a comportar 37.893 novos habitantes, quando comparados ao número de habitantes do censo 1991. No censo 2010 esse valor atingiu a marca de 75.178 novos habitantes, em comparação ao censo 2000. Esse balanço das duas últimas décadas superou inclusive o aumento populacional (em comparação ao saldo de habitantes entre um censo e outro) do município de Campos dos Goytacazes.

Tabela 2 - População dos municípios do Norte Fluminense entre 1970 e 2010.

\begin{tabular}{|c|c|c|c|c|c|}
\hline Municípios & 1970 & 1980 & 1991 & 2000 & 2010 \\
Campos dos Goytacazes & 285.440 & 320.868 & 376.290 & 406.511 & 463.731 \\
Carapebus & 8.164 & 6.834 & 7.238 & 8.651 & 13.359 \\
Cardoso Moreira & 17.958 & 14.728 & 12.819 & 12.579 & 12.600 \\
Conceição de Macabu & 11.560 & 13.624 & 16.963 & 18.706 & 21.211 \\
M acaé & $\mathbf{4 7 . 2 2 1}$ & $\mathbf{5 9 . 3 9 7}$ & $\mathbf{9 3 . 6 5 7}$ & $\mathbf{1 3 1 . 5 5 0}$ & $\mathbf{2 0 6 . 7 2 8}$ \\
Quissamã & 9.933 & 9.620 & 10.467 & 13.668 & 20.242 \\
São Fidélis & 35.143 & 34.976 & 34.581 & 36.774 & 37.543 \\
São Franciso de Itabapoana & 39.883 & 35.932 & 38.714 & 41.046 & 41.354 \\
São João da Barra & 15.736 & 18.665 & 20.847 & 27.503 & 32.747 \\
Região Norte Fluminense & 471.038 & 514.644 & 611.576 & 696.988 & 849.515 \\
\hline Adaptado pelos autores. \\
Dados dos Censos Demográficos - BGE (1970, 1980, 1991, 2000) retirado de TERRA e \\
RESSIGUIIER (2011, p. 152.)e Censo Demográfico 2010. \\
\hline
\end{tabular}

A evolução da área urbana do município de Macaé no período entre 1956 e 2001 (Figura 1), revela a acelerada expansão do crescimento populacional. Pode ser notado, em 1956, um adensamento populacional restrito à porção que corresponde ao centro da cidade. Sendo que até 1976 o principal diferencial ocorreu na ocupação da orla dos Cavaleiros. Em 1989, "onze anos após o início das obras de instalação do complexo da Petrobras no município" (PAGANOTO, 2008, p. 57), a cidade expandiu longitudinalmente. Os bairros periféricos, considerados de alta ou altíssima vulnerabilidade econômica são concomitantes ao período de 1989, fruto do intenso fluxo migratório discutido anteriormente. 


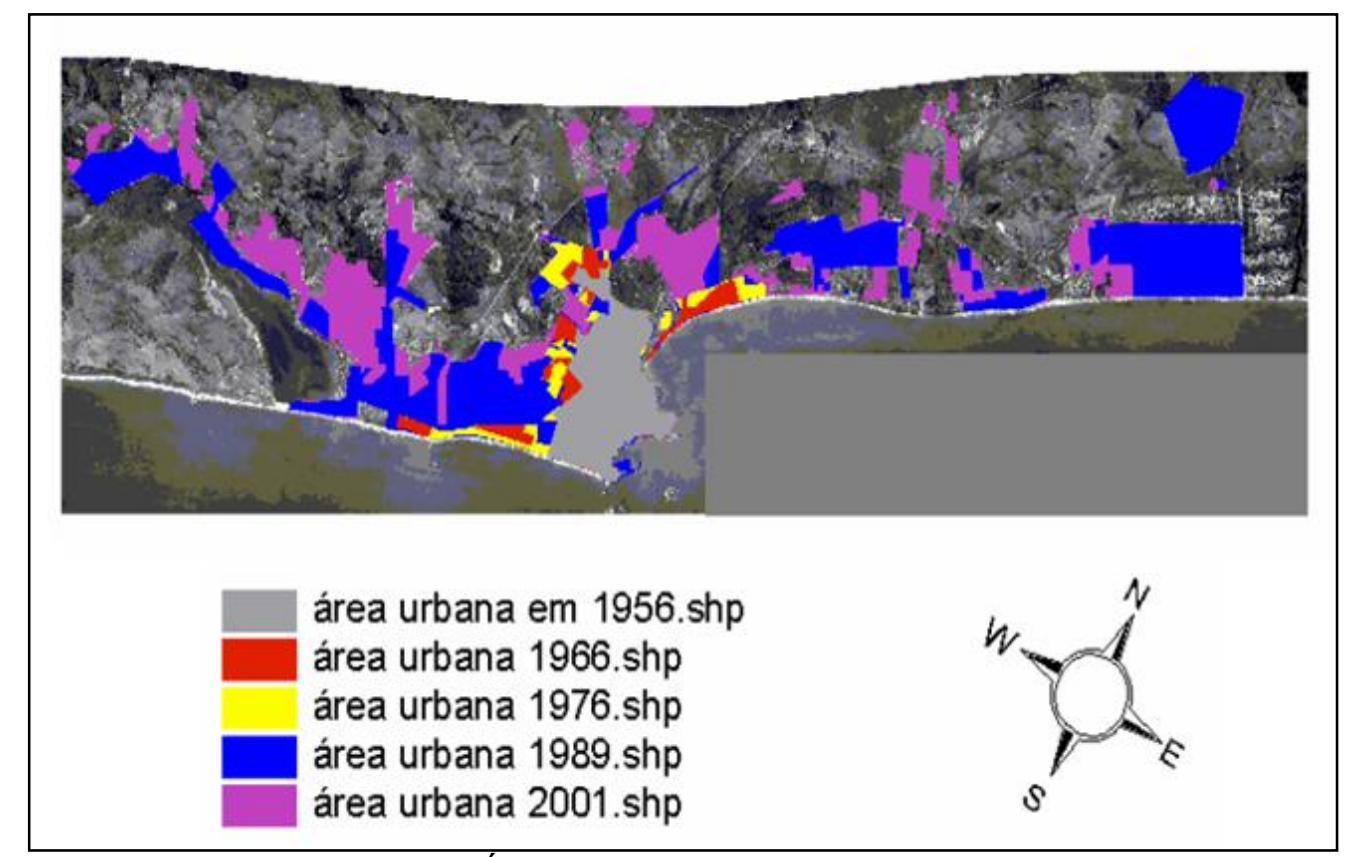

Figura 1: Mapa da Evolução da Área Urbana de Macaé - 1956/2001. Aerofotogrametria. Fonte: DIAS, 2005, p. 97.

Em estudo sobre a mobilidade espacial dos trabalhadores que migram para Macaé em função das ofertas de emprego, Paganoto (2008, p. 36) expôs que, além das vias de inserção no mercado de trabalho da região por meio de empresas terceirizadas (que realoca o trabalhador já contratado, de acordo com a demanda existente nas filiais), há também os migrantes que chegam em Macaé estimulados "pela mídia ou pelo exemplo de parentes e amigos que conseguiram inserção no mercado de trabalho, nos setores de comércio e de serviços."

A chegada no município deste segundo perfil de migrante, que muitas vezes não possui a qualificação para o seletivo mercado petrolífero ou a experiência na carteira de trabalho que as empresas do setor exigem no cargo pretendido (DIAS, 2005; FERREIRA, 2011; TERRA; RESSIGUIER, 2011), aliado a um processo de avanço estrutural sem planejamento, proporcionou o desenvolvimento desordenado das regiões periféricas em Macaé.

Em paralelo, os múltiplos impactos inerentes à cadeia produtiva petrolífera (alteração no uso do mar e da terra, especulação imobiliária, aumento populacional exponencial, aumento no custo de vida, pressão sobre unidades de conservação, demanda de infraestrutura, perda de práticas culturais e econômicas tradicionais etc.) são ideologicamente justificados em nome da geração de emprego e renda, minimizando o fato da produção econômica ser distribuída de modo desigual e ser 
efetivada sob relações de trabalho precarizadas. (CARVALHO; GUIMARÃES; DELECAVE, 2011). Por sua vez, as compensações financeiras repassadas aos municípios que sediam diretamente a base logística das atividades offshore possuem "indicadores sociais, ambientais e econômicos [que] não condizem com as altas receitas registradas há anos" (MENDONÇA, 2015, P. 302), o que evidencia um uso desvinculado dos interesses públicos.

Com isso, podemos afirmar que a ocupação industrial, nesse modo de produção dominante e sem planejamento, acarreta nos locais em que se fixa:

[...] sobrecarga nos serviços de utilidade pública, congestionamentos em horários de pico, falta d'água em bairros periféricos, enchentes constantes, escassez crescente de moradias, favelização acelerada e uso predatório do litoral, além de outras mazelas que uma ocupação industrial sem planejamento acarreta nos locais em que se fixa. (PAGANOTO, 2008, p. 6).

\section{O bairro Lagomar}

O município de Macaé possui notória divisão espacial em função da renda, visto que o centro da cidade "está ladeado por duas zonas de enormes contrastes" (HERCULANO, 2011, p. 29). Ao norte, se localizam a maior parte das periferias da região e, ao sul do município estão as moradias de luxo que abrigam os moradores de alta qualificação da cidade. A figura 2, que dispõe sobre a vulnerabilidade econômica, dos bairros existentes na porção urbana de Macaé, evidencia essa segregação socioespacial. Os bairros de maior vulnerabilidade econômica, estão situados majoritariamente ao norte, estes por sua vez, conforme discutido anteriormente, são oriundos do período de intenso fluxo migratório pós chegada da indústria petrolífera ao município. O Lagomar situa-se neste contexto.

De antemão, o bairro Lagomar possui algumas nuances em relação à condição de sua respectiva categorização. No reordenamento do município de Macaé, estruturado na lei complementar №.045/2004, o bairro Lagomar foi categorizado sob a condição de Zona de Especial Interesse Social (ZEIS). No entanto, o censo IBGE 2010, não categorizou o bairro na condição de aglomerado subnormal. Por sua vez, o programa de habitação do município denominado "Macaé 
sem Favelas"3, cujo "objetivo é acabar com as favelas e reduzir o déficit habitacional no município." (SECRETARIA DE HABITAÇÃO DE MACAÉ, [199-?], não paginado) ${ }^{4}$, prevê atendimento ao bairro Lagomar. A autora Herculano (2011) considerou determinados bairros periféricos, incluindo o Lagomar, sob a condição de áreas "favelizadas", sendo que somente algumas destas localidades são consideradas pelo censo do lbge 2010 na categoria de aglomerado subnormal. São estas: Malvinas, Nova Holanda, Santana, Leocádia e Botafogo (parte antiga).

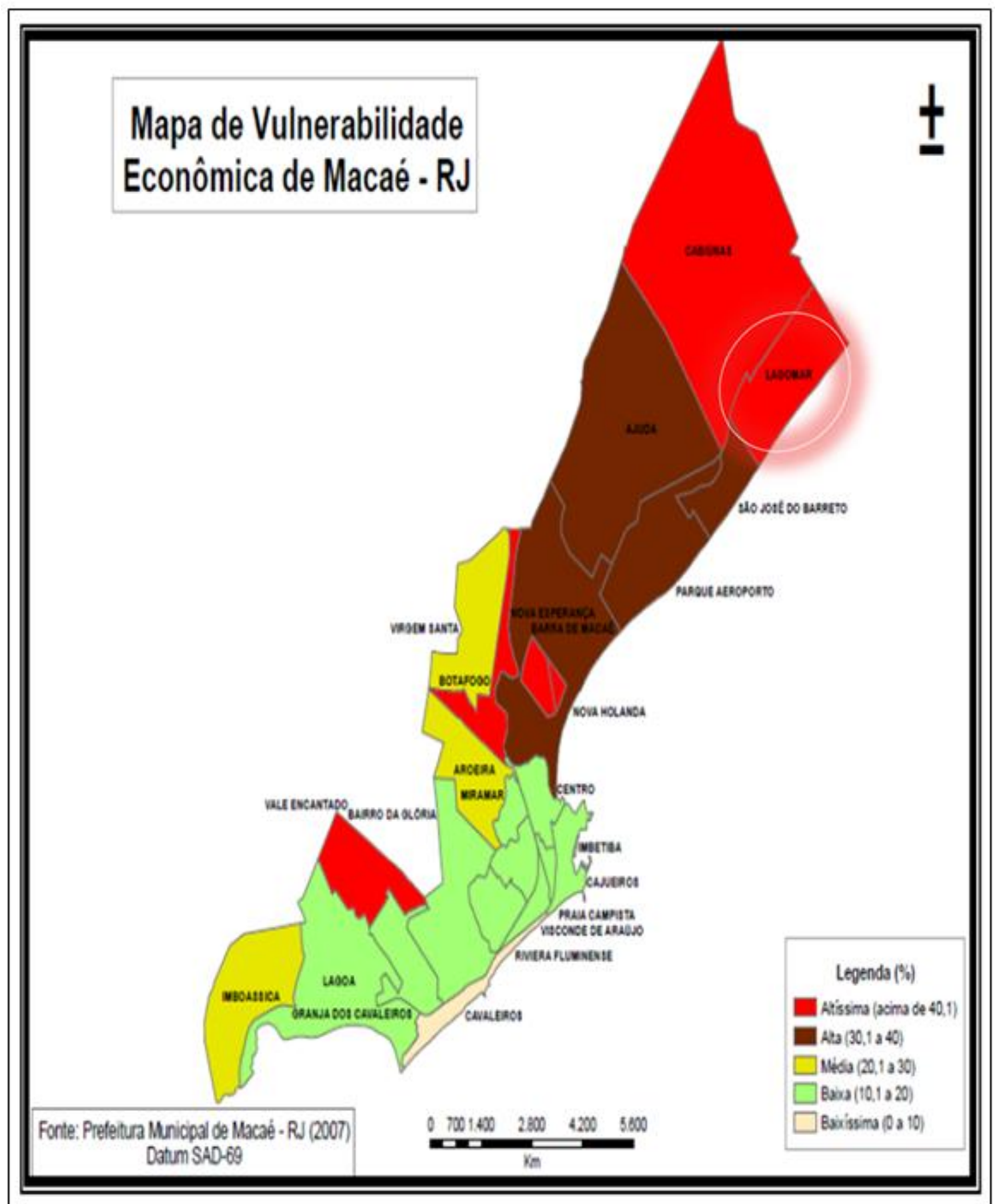

Figura 2: Mapa indicador de vulnerabilidade econômica do município de Macaé-RJ. Fonte: FERREIRA, 2011, p. 176. Em destaque (circundado) o bairro Lagomar.

\footnotetext{
${ }^{3}$ Sobre o Programa Macaé sem Favelas. "A prefeitura de Macaé vai investir mais de $\mathrm{R} \$ 300$ milhões nos próximos anos no projeto Macaé Sem Favelas, que está sendo desenvolvido pela Secretaria Municipal de Habitação. O objetivo é acabar com as favelas e reduzir o déficit habitacional no município. A prefeitura deverá totalizar cerca de 4.000 novas unidades habitacionais somente nesta administração. O Macaé Sem Favelas será implantado em três etapas: 2010/13, 2014/18 e 2019/22." Disponível em: <http://www.macae.rj.gov.br/habitacao/conteudo/titulo/macae-sem-favelas>. Acesso em: 02 Novembro 2014.

${ }^{4}$ Disponível em: http://www.macae.ri.gov.br/habitacao/conteudo/titulo/macae-sem-favelas . Acesso em: 02 Nov. 2014.
} 
Cabe ainda explicitar o caráter dual que o uso do termo favelizado pode sugestionar, "tais como formal-informal, integrado-excluído, favela-bairro, centroperiferia" (LAGO, 2003, p. 01). Mesmo que o termo seja utilizado para se referir às localidades que se desenvolveram em Macaé, enquanto resultado de um crescimento desorganizado e que de maneira mais ampla são assistidas precariamente pelos serviços públicos essenciais, tal caracterização pode abrir margem para homogeneizar diferentes contextos sociais e históricos, além de reforçar a questão do estereótipo. (ROSA, 2009).

Os autores Terra e Ressiguier (2011) apontam que esse novo Código de Urbanismo do município revela a intenção de legalizar "áreas de ocupação ambientalmente sensíveis, como as de mangue, restinga e lagoa." (Idem, p. 149). A sutil diferença, no entanto, é que as ocupações irregulares onde habitam as pessoas de baixo poder aquisitivo, como por exemplo Lagomar, Nova Esperança e Nova Holanda, foram consideradas como Zona de Especial Interesse Social enquanto que "o Mirante da Lagoa, no entorno da Lagoa de Imboassica e Ilha Caieira, em área de mangue [...] ocupadas por pessoas de maior poder aquisitivo" (Ibidem) receberam a denominação de Zona Residencial.

A partir desta comparação é percebido que áreas igualmente irregulares são assistidas de modo desigual em relação aos serviços públicos essenciais, dada a situação econômica de seus habitantes. Assim, as periferias do município, que surgem do fluxo migratório em busca dos empregos prometidos a partir da expansão da indústria do petróleo na região revelam a má distribuição desta riqueza, os impactos socioambientais e a administração inapropriada dos royalties, aplicados geralmente em áreas de benefício das classes médias e alta.

Dentre essas localidades periféricas situadas em Macaé, como dito, nos aprofundaremos na descrição do bairro Lagomar. Segundo Madeira Filho; Roriz e Silveira; (2011) dentre os bairros do município de Macaé, "Lagomar é o que mais se expande, com ocupações desordenadas, chegando a uma população de cerca de trinta mil pessoas. " (Idem. p.341).

O bairro Lagomar (620) originou-se a partir da aprovação do loteamento Balneário Lagomar, aprovado em 1976, com 527 sítios de recreio, com $5000,00 \mathrm{~m}^{2}$, o loteamento Santa Rosa foi aprovado em 1978, com 50 lotes, com área média de $600,00 \mathrm{~m}^{2}$, em 1982, foi aprovado o loteamento Parque Lagomar, conhecido como Engenho da Praia, com 589 lotes, com área 
média de 200,00 $\mathrm{m}^{2}$, e em 1983, o loteamento Praia Cigana, foi aprovado, com 127 lotes com área média de $430,00 \mathrm{~m}^{2}$. O bairro Lagomar, tem parte do seu território inserido no Parque Nacional de Jurubatiba, e na área do loteamento Balneário Lagomar, aprovado como sítios de recreio, com lotes de 5000,00 $\mathrm{m}^{2}$, surgiram invasões e loteamentos clandestinos, descaracterizando completamente a proposta original. (BARUQUI, 2004, p.39).

De acordo ainda com a autora, as habitações irregulares se originaram dentro do Balneário Lagomar, no início da década de 1990. Sendo que, desde o ano de 1997 ,

tramita no Ministério Público Federal de Campos, um processo que denuncia o parcelamento ilegal desta área, em lotes de $200 \mathrm{~m}^{2}$ ou menos, num processo que se caracteriza por uma ocupação desordenada, sem infraestrutura básica. (Idem, p.71).

Em conformidade com a lei complementar №.045/2004 - que dispõe sobre a Divisão Administrativa do Município - é considerado Bairro Lagomar o conjunto de os loteamentos compreendidos por Parque Lagomar (Engenho da Praia), Balneário Lagomar, Praia da Cigana, Santa Rosa, e parte de São José do Barreto. No entanto, cotidianamente as reportagens locais e os próprios moradores da região tratam por bairro Lagomar todo o trecho limítrofe ao Oceano Atlântico até a rodovia Amaral Peixoto. Atravessando a referida rodovia é considerado Engenho da Praia (Figura 3). Para critérios desta pesquisa foi adotada a localização geográfica a partir desta última descrição.

A área confronta-se ainda com o empreendimento do gasoduto Rota Cabiúnas, às futuras instalações do Terminal Portuário de Macaé (TEPOR) e a unidade de conservação do Parque Nacional da Restinga de Jurubatiba (PARNA). Nas localidades citadas, o bairro Lagomar encontra-se atualmente incluído dentro da área de Influência Direta. O que o dispõe em "abrangência geográfica dos impactos diretos e indiretos que este poderá acarretar aos Meios Físico, biótico e Socioeconômico." (PETROBRAS, 2011C, p.01).

Sob esta conjuntura, o Bairro Lagomar encontra-se susceptível:

aos riscos ambientais associados à proximidade do Terminal de Cabiúnas, que processa e distribui o petróleo e o gás produzido na Bacia de Campos [e por estar adicionalmente localizada em] área limítrofe e zona de amortecimento do Parque Nacional Restinga de Jurubatiba (PARNA Jurubatiba) [...] contemplado pela Lei 9.985/ 2000 (BRASIL, 2000), a qual 
define que as atividades humanas a serem desenvolvidas na região estão sujeitas a restrições e a um mínimo impacto ambiental negativo. (FERREIRA, 2011, p.181).

Na Figura 3 é possível visualizar o percurso dos dutos, localizados entre o Parque Nacional da Restinga de Jurubatiba e o bairro Lagomar. Mais especificamente referente a localização do gasoduto terminal Cabiúnas:

o trecho marítimo se inicia no norte da Bacia de Santos percorrendo cerca de $378 \mathrm{~km}$ até a chegada na praia do Lagomar, por onde segue, por uma "faixa de dutos já existente, paralela ao Parque Nacional da Restinga de Jurubatiba, por aproximadamente $5 \mathrm{~km},[\ldots]$ até chegar ao terminal". (PETROBRAS 2011B, p.03).
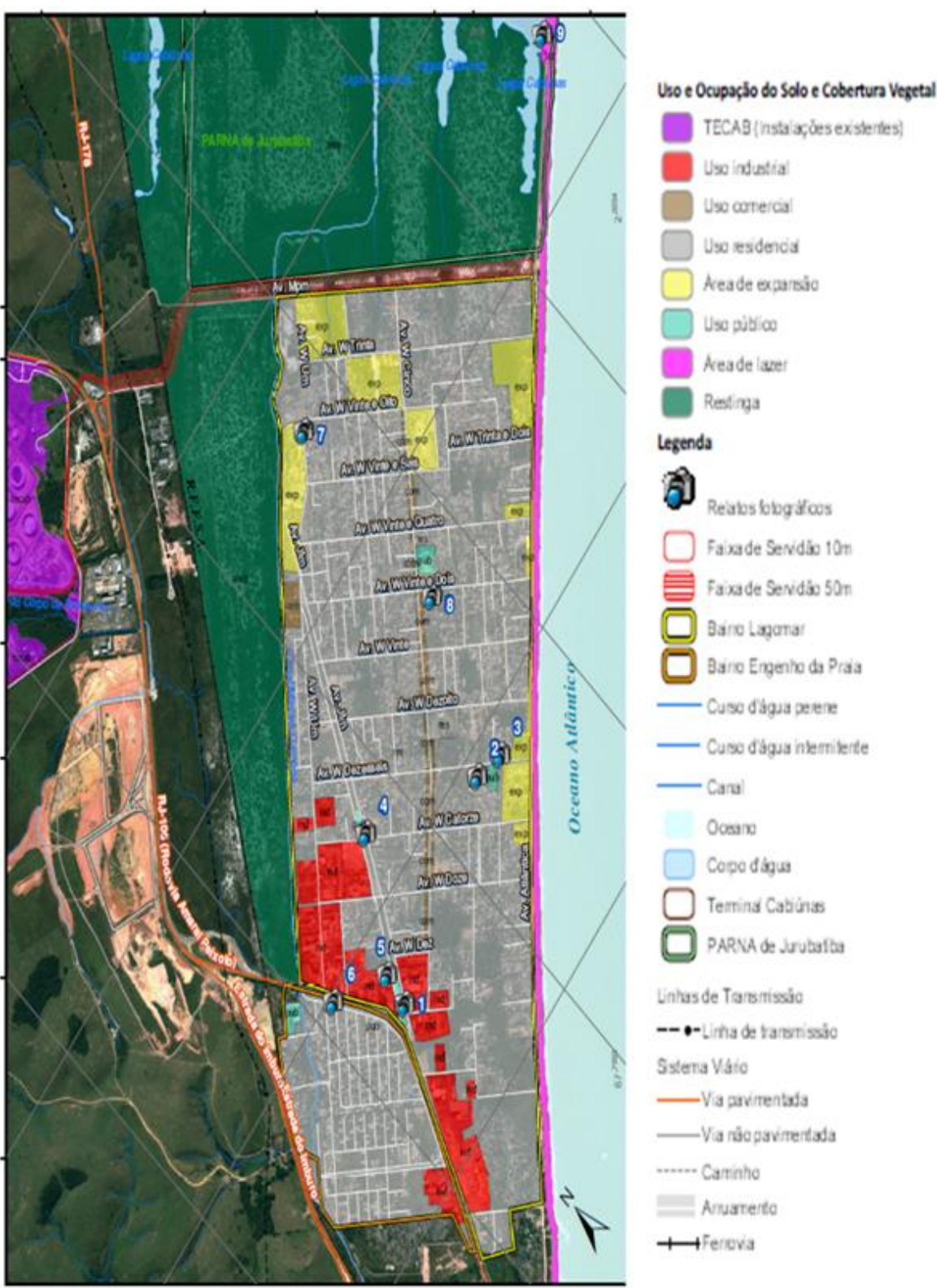

Figura 3 - Mapa do bairro Lagomar, em Macaé em função do uso e ocupação do solo. Fonte: PETROBRAS. 2011D, p. 08. 
A consulta ao estudo de impacto ambiental do gasoduto Rota Cabiúnas (PETROBRAS. 2011A.) nos permitiu compreender a ocupação do solo no bairro Lagomar. Este estudo indicou a utilização por uso residencial (38,30\%) como principal ocupação deste território, seguida da área de restinga $(37,45 \%)$, representada pela existência do Parque Nacional (PARNA) da Restinga de Jurubatiba.

Tabela 3 - Percentual de uso e ocupação do solo no bairro Lagomar, em Macaé/RJ.

\begin{tabular}{|l|r|r|}
\hline \multicolumn{1}{|c|}{ Classes } & Área $\left(\mathrm{m}^{2}\right)$ & $\begin{array}{c}\text { Percentual } \\
(\%)\end{array}$ \\
\hline Uso industrial & 340.692 & 3,88 \\
\hline Uso comercial & 46.366 & 0,53 \\
\hline Área de lazer & 203.114 & 2,31 \\
\hline Área de expansão & 307.450 & 3,50 \\
\hline Uso public & 29.194 & 0,33 \\
\hline Restinga & 3.290 .704 & 37.45 \\
\hline Uso residencial & 3.364 .962 & 38,30 \\
\hline Área de servidão dos dutos existentes & & \\
\hline TOTAL & 8.786 .603 & 100,00 \\
\hline
\end{tabular}

Fonte: PETROBRAS. 2011D, p. 11.

A zona industrial (3,88\%) presente no bairro (mais especificamente centralizada na entrada do mesmo) veio a ocorrer em função da proximidade da respectiva área com a Rodovia Amaral Peixoto (RJ-106) e o Terminal Cabiúnas. A porcentagem em relação à área de lazer (2,31\%) do uso de ocupação do solo do bairro Lagomar, chama a atenção visto que o estudo também incluiu no percentual do cálculo, a área de lagoa localizada dentro do Parque Nacional da restinga de Jurubatiba.

"Além da ampla faixa litorânea [...] a população utiliza a lagoa localizada no Parque Nacional da Restinga como alternativa de lazer. Essa área é citada como principal local de entretenimento da comunidade, que se encontra distante dos principais centros de lazer do município." (PETROBRAS, 2011D, p.12).

No entanto, a utilização do parque como área de lazer é conflituosa e explicita a tensão existente entre a população de entorno do parque, do bairro Lagomar, e o parque nacional propriamente dito. No plano de manejo do Parque Nacional da 
restinga de Jurubatiba (2007), a "Presença de pessoas no interior do Parque" foi considerada como "atividades conflitantes" (Idem. p.16), onde viriam a ocorrer sem regulação, ainda segundo o documento, atividades de "banho, passeios de bugre e caminhadas." (Ibidem).

Posteriormente, a Portaria $\mathrm{n}^{\circ}$ 01, de 05 de janeiro de 2012, que buscou "Estabelecer normas e procedimentos [...] com fins turísticos no Parque Nacional da Restinga de Jurubatiba - PARNA Jurubatiba." (BRASIL. 2012, p.01), explicitou que a visitação só deveria ocorrer em trechos restritos com o objetivo de gerar impactos menores. No entanto, as normas de visitação de maneira geral, que inclusive especificam dias e horários em que o parque se encontra aberto ao público, somente existem no plano legal, visto a falta de infraestrutura para ser fazer cumprir o respectivo regimento, gerando usos em locais variados com eventual repressão da fiscalização do Instituto Chico Mendes de Conservação da Biodiversidade (ICMBio).

Além dos problemas ambientais, e de sua constituição como área de habitação irregular, ocupada por famílias em situação de precariedade econômica e de frágil garantia de direitos sociais elementares (saúde, educação e segurança pública), no referido bairro há o desencadeamento de agravantes sanitários associados à precariedade de saneamento e água canalizada. Por possuir habitações assentadas "sobre solos arenosos, ou seja, de alta permeabilidade com lençol freático elevado em alguns trechos" (FERREIRA, 2011, p.181) e instalações precárias de saneamento básico ${ }^{5}$, os poços escavados na localidade para 0 abastecimento de água, encontram-se impróprios para o consumo.

Os avanços das habitações irregulares, sob as condições de infraestrutura acima descritas resultam em alto impacto ambiental, o que confronta a legislação ambiental prevista para uma área que é tida como zona de amortecimento do Parque Nacional da Restinga de Jurubatiba. (BARUQUI, 2004).

A existência do bairro Lagomar (que data de 1976, com processos de habitação irregular a partir de 1990) é anterior à criação do Parque Nacional de Jurubatiba, que data de 1998, sendo que a referida unidade de conservação trata o bairro como uma ameaça e desconsiderou as necessidades deste no seu ato de criação institucional e na forma de fazer a gestão territorial e política, reproduzindo

\footnotetext{
${ }^{5}$ De acordo com dados da pesquisa domiciliar do programa Macaé Cidadão - 2006/2007, e apontados por Terra e Ressiguier (2011), 56,5\% do esgoto destinado a fossa rudimentar e ausência de $63,1 \%$ de água canalizada.
} 
um modo de se fazer a política de conservação no país que tende a contrapor sociedade-natureza. O que alia o novo padrão de acumulação empreendido por meio do setor produtivo petrolífero à ocorrência de injustiça ambiental no município. Tal afirmação corrobora pesquisa anterior feita, que conclui:

"O cruzamento de dados de risco de contaminação por poluentes industriais, com os de localização de empreendimentos industriais associados à cadeia produtiva do petróleo e gás e com os padrões de crescimento desordenado e desigualdade social evidenciados no município, confirmaria a hipótese de ocorrência de injustiça ambiental no município, associada aos impactos secundários e indiretos da indústria do petróleo". (FERREIRA, 2011, p.179).

Em uma sociedade desigual na sua forma de produzir e distribuir riquezas e no ordenamento espacial de grupos e classes sociais, pensar as políticas de conservação desconsiderando a história social torna a criação de unidades de conservação de proteção integral funcional aos mecanismos de dominação e de injustiça ambiental (LOUREIRO, 2014; MOUTINHO DA COSTA, 2011), ignorando que a função de proteção à biodiversidade só pode ser garantida com 0 reconhecimento e atendimento à função social de tais áreas protegidas.

\section{CONCLUSÕES}

O município de Macaé/RJ é um exemplo claro de como o modelo de desenvolvimento cultivado no Brasil alia um padrão de acumulação baseado na reprimarização da economia e na produção de commodities à ocorrência de injustiça ambiental. Esse padrão, no caso estudado, gera aguda transformação espacial desde a implantação da cadeia produtiva do petróleo e seus processos econômicos e sociais diretos e indiretos, localizando de modo muito demarcado as "áreas de ricos" e as "áreas de pobres".

O bairro Lagomar, entre outros bairros periféricos na região, que se desenvolvem em áreas ambientalmente sensíveis para fins de habitação, vivem sob condições precárias de infraestrutura e alta vulnerabilidade econômica. O que tipifica os mecanismos de reprodução da dominação social e a existência de forte componente racial e classista na distribuição desigual dos danos e impactos 
ambientais derivados das formas de uso e apropriação da natureza legitimadas pela centralidade da exploração petrolífera para o município de Macaé.

Por fim, com as evidências apresentadas nesse e em outros trabalhos aqui referenciados, é possível afirmar a ocorrência de injustiça ambiental e social em Macaé/RJ, a qual se reflete de modo mais agudo nas condições de vida dos moradores do Bairro Lagomar, recorte da pesquisa. Assim, a produção desigual do território, mediada pelo capital e pelo Estado, determina que as classes menos favorecidas habitem áreas com qualidades ambientais "sacrificadas", em nome do desenvolvimento industrial.

\section{Referências}

ACSELRAD, H. O que é justiça ambiental. Rio de Janeiro: Garamond, 2009.

ACSELRAD, H. Conflitos ambientais no Brasil. Rio de Janeiro: Relume Dumará, 2004.

ALTVATER, E. O fim do capitalismo como o conhecemos. Rio de Janeiro: Civilização Brasileira, 2010.

BARCELOS, D. R. Complexo Portuário do Açu: o município de São João da Barra/RJ na rota logística do novo padrão de desenvolvimento regional brasileiro. Boletim Petróleo, Royalties e Região, Campos dos Goytacazes, ano XIII, n. 49, set. 2015.

BARUQUI, S.S.C. A cidade formal e a cidade informal em Macaé: Uma análise do crescimento habitacional na década de 90. 2004. Dissertação (Mestrado em Planejamento Regional e Gestão de Cidades) - Universidade Candido Mendes, Campos dos Goytacazes, RJ, 2004.

BRASIL. Instituto Chico Mendes de Conservação da Biodiversidade - ICMBio. Portaria no 01, de 05 de janeiro de 2012. Estabelece normas e procedimentos para 0 credenciamento e autorização dos serviços de condução de visitantes, transporte em barco e transporte em veículo tracionado, com fins turísticos no Parque Nacional da Restinga de Jurubatiba - PARNA Jurubatiba. 2012.

BRASIL. Instituto Chico Mendes de Conservação da Biodiversidade - ICMBio. Plano de Manejo do Parque Nacional da Restinga de Jurubatiba. 2007.

CARVALHO, T.; GUIMARÃES, W.; DELECAVE, J. Repercussões da exploração petrolífera sobre as transformações urbanas de Macaé (RJ). In HERCULANO, S. (Org.). Impactos Sociais, Ambientais e Urbanos das Atividades Petrolíferas: 0 
caso de Macaé (RJ). Niterói: Programa de Pós-Graduação em Sociologia e Direito (PPGSD) da Universidade Federal Fluminense, 2011. p. 220-239.

DIAS, R. A formação de uma aglomeração industrial em Macaé, RJ: uma caracterização da espacialidade da indústria petrolífera e seus impactos no espaço urbano macaense e sua região de entorno. Campos dos Goytacazes: CEFET/Campos, 2005.

FERREIRA, M. I. P. A sociedade do hidrocarboneto: o ônus do aquecimento econômico gerado pela cadeia produtiva do petróleo e gás em Macaé - RJ. In HERCULANO, S. (Org.). Impactos sociais, ambientais e urbanos das atividades petrolíferas: o caso de Macaé (RJ). Niterói: Programa de Pós-Graduação em Sociologia e Direito (PPGSD) da Universidade Federal Fluminense, 2011. p. 169187.

HARVEY, D. A produção capitalista do espaço. São Paulo: Annablume, 2005.

HERCULANO, S. Desenvolvimento local, responsabilidade socioambiental e royalties: a Petrobras em Macaé (RJ). In: HERCULANO, S. (org.) Impactos sociais, ambientais e urbanos das atividades petrolíferas: o caso de Macaé (RJ). Niterói: Programa de Pós-Graduação em Sociologia e Direito (PPGSD) da Universidade Federal Fluminense, 2011. p. 19-46.

HERNÁNDEZ, F. M; BERMANN, C. A expansão da fronteira de exploração petrolífera: consequências sobre territórios e populações tradicionais. In: ALMEIDA, A. W. B. de. et.al. Capitalismo globalizado e recursos territoriais: fronteiras da acumulação no Brasil contemporâneo. Rio de janeiro: Lamparina, 2010.

INSTITUTO BRASILEIRO DE GEOGRAFIA E ESTATÍSTICA (IBGE). 2010. Aglomerados subnormais. Disponível em:

<http://www.censo2010.ibge.gov.br/agsn/>. Acesso em: 19 nov. 2014.

LAGO, L. C. "Favela-loteamento: re-conceituando os termos da ilegalidade e da segregação urbana". X Encontro Nacional da ANPUR (Anais). Belo Horizonte, 2003.

LOUREIRO, C. F. B. Sustentabilidade e educação: um olhar da ecologia política. 1ํㅡ reimp. da 1. ed. São Paulo: Cortez, 2014.

MADEIRA FILHO, W.; RORIZ, J. E.; SILVEIRA, A. A. da. Poluição cívica criminalização do bairro Lagomar no município de Macaé e ajustamentos de conduta. In HERCULANO, S. (Org.). Impactos sociais, ambientais e urbanos das atividades petrolíferas: 0 caso de Macaé (RJ). Niterói: Programa de PósGraduação em Sociologia e Direito (PPGSD) da Universidade Federal Fluminense, 2011. p. 339-367.

MENDONÇA, G. M. de. O Brasil licenciando e andando: as relações da política pública ambiental brasileira com a produção e a expansão capitalista do 
território. 2015. Tese - (Doutorado em PPG em Políticas Públicas, Estratégias e Desenvolvimento), Universidade Federal do Rio de Janeiro, Rio de Janeiro, 2015.

MOUTINHO DA COSTA, L. Territorialidade e racismo ambiental: elementos para se pensar a educação ambiental crítica em unidades de conservação. Revista Pesquisa em Educação Ambiental: UNESP, Rio Claro, v. 6, n. 1, 2011.

PACHECO, Carlos Augusto Góes. O impacto dos royalties do petróleo no desenvolvimento econômico dos municípios da região norte fluminense. $3^{\circ}$ Congresso Brasileiro de P\&D em Petróleo e Gás. Instituto Brasileiro de Petróleo e Gás - IBP. 2005. Disponível em:

<http://www.portalabpg.org.br/PDPetro/3/trabalhos/IBP0181_05.pdf>. Acesso em: 01 nov. 2015.

PAGANOTO, F. Mobilidade e trabalho em Macaé/RJ, a "capital do petróleo". Dissertação. 2008. Dissertação. (Mestrado em Geografia) - Universidade Federal do Rio de Janeiro, Rio de Janeiro, 2008.

PETROBRAS. Estudo de Impacto Ambiental do Gasoduto Rota Cabiúnas. Apresentação. 2011A.

PETROBRAS. Estudo de Impacto Ambiental do Gasoduto Rota Cabiúnas. Caracterização da atividade. 2011B.

PETROBRAS. Estudo de Impacto Ambiental do Gasoduto Rota Cabiúnas.. Área de Influência do Empreendimento. 2011C.

PETROBRAS. Estudo de Impacto Ambiental do Gasoduto Rota Cabiúnas. Diagnóstico Ambiental - Meio Socioeconômico. 2011D.

PMM - Prefeitura Municipal de Macaé. Pesquisa domiciliar sobre o perfil e o anseio das famílias macaense, 2006-2007. Macaé: Programa Macaé Cidadão, 2010.

PREFEITURA MUNICIPAL DE MACAÉ. Plano Local de Habitação de Interesse Social (PLHIS). Diagnóstico das Necessidades Habitacionais e Estratégias de Ação. 2010.

PREFEITURA MUNICIPAL DE MACAÉ. Da divisão administrativa do município de Macaé. Lei complementar №.045/2004. Consolida as Leis Municipais nํ. 006/1998, 012/1999 e 017/1999, que dispõem sobre a Divisão Administrativa do Município, promove novo ordenamento territorial, expandindo a zona urbana, e dá outras providências. 2004.

PREFEITURA MUNICIPAL DE MACAÉ. Código de urbanismo. Lei complementar no $141 / 2010$. Dispõe sobre o Código de Urbanismo do Município de Macaé e dá outras providências. 2010. 
ROSA, T. T. Favelas, Periferias: uma reflexão sobre conceitos e dicotomias. Anais do 33 ncontro Anual da Anpocs. 2009

SIRELLI, P.M.; OLIVEIRA, R.C. de.; CAMPOS, K. M.; SILVA, H. J. Trabalho reestruturação do capital e mercado de trabalho em Macaé. Pauta - Revista da Faculdade de Serviço Social da Universidade do Estado do Rio de Janeiro, Rio de Janeiro, n. 30, v. 10, p. 187-207, $2^{\circ}$ Semestre, 2012. Disponível em: <http://www.puro.uff.br/observatoriodotrabalho_mercado>. Acesso em: 23 jun. 2013.

TERRA, D. C. T.; RESSIGUIER, J. H. Mudanças no Espaço Urbano de Macaé: 1970-2010. In HERCULANO, S. (Org.). Impactos sociais, ambientais e urbanos das atividades petrolíferas: o caso de Macaé (RJ). Niterói: Programa de PósGraduação em Sociologia e Direito (PPGSD) da Universidade Federal Fluminense, 2011. p. 149-168. 